\title{
A diagnosis of hypochondroplasia by next generation sequencing
}

Seok Min Ahn, Young Han Kim, Jun Woo Baek, Eun Ju Bae, and Hong Jin Lee*

Department of Pediatrics, Hallym University Chuncheon Sacred Heart Hospital, Chuncheon, Korea

Achondroplasia and hypochondroplasia are the two most common forms of short-limb dwarfism. They are autosomal dominant diseases that are characterized by a rhizomelic shortening of the limbs, large head with frontal bossing, hypoplasia of the mid-face, genu varum and trident hands. Mutations in the fibroblast growth factor receptor-3 (FGFR3) gene, which is located on chromosome 4p16.3, have been reported to cause achondroplasia and hypochondroplasia. More than $98 \%$ of achondroplasia cases are caused by the G380R mutation (c.1138G $>$ A or c.1138G >C). In contrast, the N540K mutation (c.1620C $>A$ ) is detected in 60-65\% of hypochondroplasia cases. Tests for common mutations are often unable to detect the mutation in patients with a clinical diagnosis of hypochondroplasia. In this study, we presented a case of familial hypochondroplasia with a rare mutation in FGFR3 identified by next generation sequencing.

Key words: Achondroplasia, Hypochondroplasia, Dwarfism, Receptor, fibroblast growth factor, type 3, High-throughput nucleotide sequencing.

\section{Introduction}

Achondroplasia (ACH; OMIM \# 100800) and hypochondroplasia ( $\mathrm{HCH} ; \mathrm{OMIM} \# 146000)$ are the two most common autosomal dominant skeletal dysplasias characterized by short-limb dwarfism [1]. Patients with ACH typically show characteristic phenotypes at birth including relative macrocephaly, midface hypoplasia, rhizomelic shortening of the limbs, brachydactyly, narrowing of the spinal canal, lumbar lordosis, and genu varum. $\mathrm{HCH}$, a milder form of $\mathrm{ACH}$, causes a less severe phenotype, which is typically not evident before 2 years of age [2,3].

Both $\mathrm{ACH}$ and $\mathrm{HCH}$ are caused by missense mutation in the fibroblast growth factor receptor-3 gene (FGFR3) located on chromosome 4p16.3 [4]. Recent studies reported that more than $98 \%$ of patients with ACH have a glycine-to-arginine substitution at residue 380 (G380R) of FGFR3, located within the FGFR3 transmembrane domain, as a result of guanine $(\mathrm{G})$ to adenine (A) or cytosine (C) mutation at nucleotide 1,138 of the FGFR3 gene [5]. In the case of $\mathrm{HCH}$, only $65 \%$ of patients have the common asparagine-to-lysine substitution (N540K), located in the FGFR3 tyrosine kinase domain, caused by a $\mathrm{C}$ to $\mathrm{A}$ mutation at position 1,620 [5]. It is thought that the unaccounted $\mathrm{HCH}$ cases may be caused by a yet-to-be identified mutation in FGFR3 or a different gene.

The proband patient in this study was a 28-month-old female child who presented the typical $\mathrm{HCH}$ phenotype, with no common $\mathrm{ACH}$ or $\mathrm{HCH}$ mutation detected. After a verbal informed consent was received from parents, the genomic DNA was isolated from the peripheral blood of the patient using the SureSelect Human All Exon Kit (Agilent Technologies, Santa

Received: 30 March 2016, Revised: 1 June 2016, Accepted: 1 June 2016, Published: 30 June 2016

*Corresponding author: Hong Jin Lee, M.D.

Department of Pediatrics, Hallym University Chuncheon Sacred Heart Hospital, 77 Sakju-ro, Chuncheon 24253, Korea.

Tel: +82-33-240-5000, Fax: +82-33-255-6244, E-mail: hjlee@hallym.or.kr

Conflict of interest: The authors declare that they do not have any conflicts of interest.

(ac) This is an open-access article distributed under the terms of the Creative Commons Attribution Non-Commercial License (http://creativecommons.org/licenses/by-nc/4.0/) which permits unrestricted non-commercial use, distribution, and reproduction in any medium, provided the original work is properly cited.

(c) Copyright 2016 by the Korean Society of Medical Genetics 
Clara, CA, USA). A sequence analysis was carried out using a HiSeq 2000 sequencing system (Illumina, San Diego, CA, USA). An S84L amino acid substitution of FGFR3 was identified in the patient. In this study, we reported the first $\mathrm{HCH}$ case with an S84L mutation in FGFR3 in Korea, identified using next generation sequencing .

\section{Case}

A 28-month-old female child was referred to the Department of Pediatrics of the Hallym University Chuncheon Sacred Heart Hospital (Chuncheon, Korea) for an evaluation of short stature and genu varum. She was born to non-consanguineous parents after 40 weeks of gestation by spontaneous vaginal delivery without perinatal complications. The patient's birth weight was $3.2 \mathrm{~kg}$ (25-50th percentile), and there was no developmental delay or intellectual disability reported. The patient is the second of four children of a Korean father and a Filipino mother. Her height and weight on referral were $87 \mathrm{~cm}$ (25th percentile) and $16 \mathrm{~kg}$ (90-97th percentile), respectively. Her father has a short stature of approximately $155 \mathrm{~cm}(<3 \mathrm{rd}$ percentile) and a mild rhizomelic shortening of the limbs without any other orthopedic deformities. The height of the patient's mother, brother, and twin younger sisters' was within the normal range. The height of the mother and twin sisters' was $155 \mathrm{~cm}$ (10-25th percentile), $82.4 \mathrm{~cm}$ (75-90th percentile), and $76.4 \mathrm{~cm}$ (10-25th percentile), respectively with no morphological abnormalities. The height of the older brother was not evaluated.

During the physical examination, a mild mid-facial hypoplasia, rhizomelic shortening of extremities, genu varum, and lumbar lordosis were observed; however, the result of a neurologic examination was normal (Fig. 1). Laboratory examinations showed normal blood cell count and thyroid function. Other endocrinology laboratory findings were within the normal range, including an insulin-like growth factor 1 level of 129.2 $\mathrm{ng} / \mathrm{mL}$, a cortisol level of $3.3 \mu \mathrm{g} / \mathrm{dL}$, an ACTH level of $8.5 \mathrm{pg} / \mathrm{mL}$, and a 25-hydroxyvitamin D level of $14.6 \mathrm{ng} / \mathrm{mL}$. A toluidine blue urine spot test for mucopolysaccharidosis was also performed and the result showed no abnormality relative to those observed in the same age group. Skeletal radiographs, including those of the paranasal sinus (PNS), chest, whole spine, both hands, forearms, and knees, were obtained. Radiographs of the PNS and both hands showed normal findings (Figs. 2A-C). The spinal anteroposterior (AP) X-ray showed normal interpedicular distances; however, a lumbar lordosis with horizontally tilted sacrum was apparent in the lateral view (Figs. 2D and E). Radiographs of forearms and knees showed normal findings.

Typically, when ACH or $\mathrm{HCH}$ is suspected based on clinical symptoms of the patient, we first assess the presence of the G380R mutation (G1138A or G1138C) in a genetic analysis. However, neither of the two major mutations was detected in the proband patient. We subsequently sequenced six exons
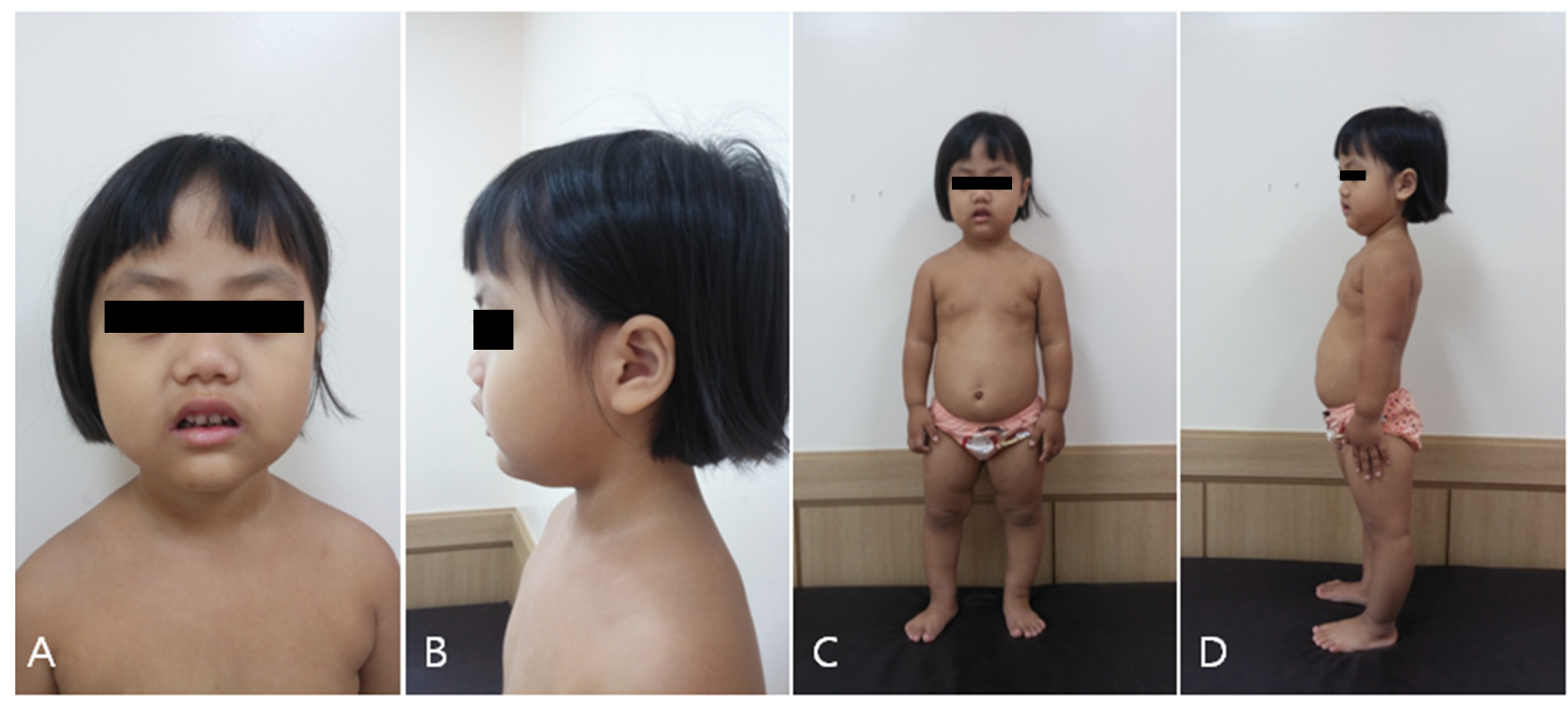

Fig. 1. Photographs of a 28-month-old female child with hypochondroplasia. (A, B) Photographs showing mild mid-facial hypoplasia, which is especially apparent in the lateral view. (C) All extremities show relatively short proximal limbs (when compared to the distal parts) and genu varum. (D) A lateral photographs of the patient shows excessive lumbar curvature and a sacral lesion of the spine. 

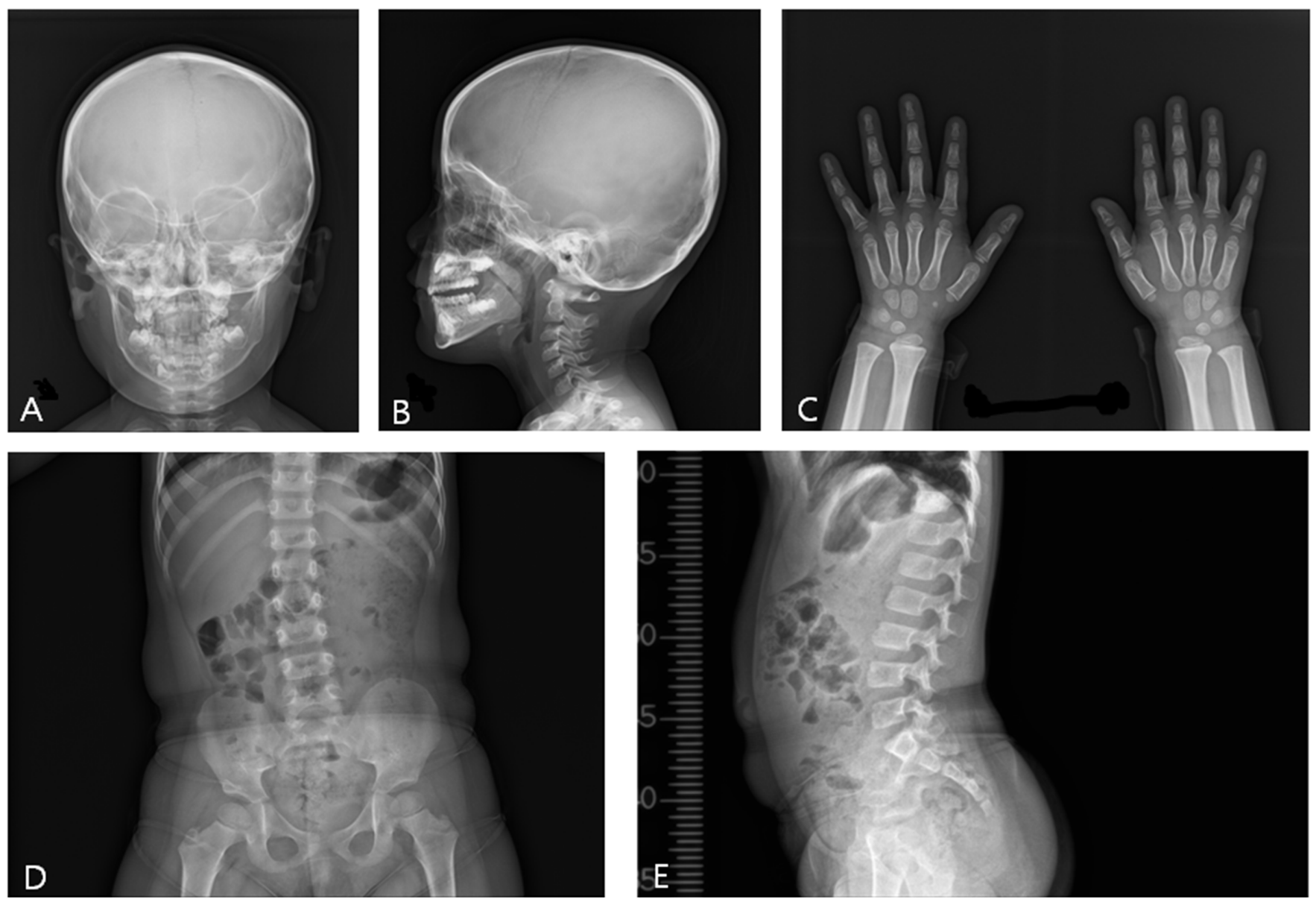

Fig. 2. Radiographs of the patient. (A, B) Anteroposterior (AP) and lateral views of the paranasal sinus show no abnormal findings. (C) An AP view of both hands shows no trident fingers. (D) A lumbosacral spine radiograph shows normal interpedicular distances. (E) A lateral view lumbosacral spine radiograph shows lumbar lordosis.

(exon 6, 7, 8, 11, 13, and 17) of FGFR3, which include sites often mutated in $\mathrm{ACH}$ and $\mathrm{HCH}$. However, none of the common mutations, including Y373C, G380R, N540S, and K650N, was found in the patient. Therefore, a whole genome analysis was performed by next generation sequencing to identify a mutation in other gene or elsewhere in FGFR3. In the analysis, for the first time in Korea, we found a c.251C > T mutation in FGFR3 resulting in a S84L amino acid substitution associated with $\mathrm{HCH}$. The patient's father, but not her mother or three siblings, was also found to carry the same FGFR3 mutation, as assessed by a genetic analysis using next generation sequencing.

\section{Discussion}

The FGFR3 gene is located on chromosome 4p16.3 and consists of 18 coding exons [6]. The FGFR3 gene encodes for a transmembrane tyrosine kinase receptor that binds to fibroblast growth factors. The protein has three extracellular immunoglobulin-like domains (Ig-like domains I-III), a transmembrane domain, and an intracellular tyrosine kinase domain [6]. FGFR3 has essential roles in the regulation of chondrocyte differentiation, proliferation, and apoptosis, and has been reported to regulate endochondral ossification during a normal skeletal development through a negative feedback mechanism [7,8]. An FGFR3 gain-of-function mutation was reported to negatively affect both the proliferation and differentiation of the growth plate chondrocytes, causing various forms of skeletal dysplasia, including $\mathrm{HCH}, \mathrm{ACH}$, and lethal thanatophoric dysplasia (OMIM \# 187600), depending on the severity of symptoms $[9,10]$.

ACH has an estimated prevalence of one in 16,000-26,000 live births [6]. The clinical manifestations of ACH include bulging forehead and a rhizomelic shortening of the limbs with a subsequent development of lumbar lordosis and genu varum [11]. Radiographic findings include a shortening of the base of the skull with a small foramen magnum, a reduced spinal 
canal size throughout its length, a flared metaphysis of the long bones, a decrease in interpedicular distances from the first to fifth lumbar vertebral bodies, and an AP shortening of the lumbar pedicles [11,12]. A narrowing of the spinal canal in the thoracolumbar and lumbar regions often causes neurological issues, resulting in spinal stenosis, which can progress paralysis [11].

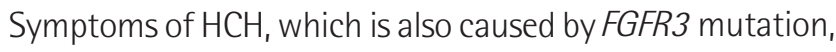
are similar to those of $\mathrm{ACH}$ with the exception of less severe changes in the skull and phenotype when compared to those observed in ACH [11]. Lamy and Maroteaux [13] suggested the use of term HCH for this syndrome. Beals [14] reported five kindred cases, which were classified as $\mathrm{HCH}$. The study reported limb shortening without rhizomelia, mesomelia, or acromelia, and a mild metaphyseal flaring in the five cases. Brachydactyly and mild limitation of elbow extension were apparent in these patients. The typical manifestations observed included an AP shortening of the lumbar pedicles, unchanged or caudal narrowing of the spinal canal, and a noticeable lumbar lordosis. Specht and Daentl [15] subsequently reported six additional cases of $\mathrm{HCH}$ displaying rhizomelic shortening of the limbs with a normal craniofacial and hand appearance.

Both $\mathrm{ACH}$ and $\mathrm{HCH}$ are allelic disorders caused by mutation in FGFR3. Bellus et al. [16] identified recurrent mutations associated with $\mathrm{HCH}$. In the study, a specific mutation in the tyrosine kinase domain of FGFR3 was identified in eight of 14 unrelated patients with $\mathrm{HCH}$ [16]. The nucleotide at position 1,620 of FGFR3 was mutated from $\mathrm{C}$ to A resulting in an N540K substitution. Because six of the 14 patients did not carry the N540K substitution, it was determined that $\mathrm{HCH}$ can be caused by an unidentified mutation in other gene or elsewhere in FGFR3. To identify novel FGFR3 mutations, Heuertz et al. [17] conducted a study on a cohort of $25 \mathrm{HCH}$ and one $\mathrm{ACH}$ patients in whom the common FGFR3 mutations were ruled out. Seven novel mutations were found, including the Y278C, G268C, R200C, N262H, V381E, S84L substitutions for $\mathrm{HCH}$, and $\mathrm{S} 279 \mathrm{C}$ for $\mathrm{ACH}$ [17]. Mutations that resulted in an amino acid substitution to cysteine were found to cause more severe phenotypes. The S84L mutation was located in the extracellular Ig-like I domain of FGFR3. In the particular case reported by Heuertz et al. [17], the mother and grandfather of the patient also had the S84L mutation.

In this study, we identified the first case of S84L mutation in Korea. Only one case with this mutation was reported outside Korea [17]. ACH and $\mathrm{HCH}$ are typically diagnosed based on clinical symptoms and radiographic findings; however, there are no definite diagnostic biomarkers available. Thus, it is essential to sequence the mutation hotspots in FGFR3 first, and in cases where the common mutations are not found, a whole exome analysis can be subsequently performed in order to identify other mutation(s) in FGFR3 for both diagnosis and genetic counseling purposes.

\section{References}

1. Grigelioniené G, Hagenäs L, Eklöf $O$, Neumeyer L, Haereid PE, Anvret M. A novel missense mutation lle538Val in the fibroblast growth factor receptor 3 in hypochondroplasia. Hum Mutat 1998;11:333.

2. Winterpacht $A$, Hilbert $K$, Stelzer $C$, Schweikardt T, Decker $H$, Segerer $H_{\text {, }}$ et al. A novel mutation in FGFR-3 disrupts a putative N-glycosylation site and results in hypochondroplasia. Physiol Genomics 2000;2:912.

3. Deutz-Terlouw PP, Losekoot M, Aalfs CM, Hennekam RC, Bakker E. Asn540Thr substitution in the fibroblast growth factor receptor 3 tyrosine kinase domain causing hypochondroplasia. Hum Mutat 1998:Suppl 1:S62-5.

4. Shin S, Choi IH, Cho TJ, Ryang SW, Yoon KY, Kim J, et al. Mutation analysis of fibroblast growth factor receptor 3 (FGFR3) gene in Korean patients with achondroplasia and hypochondroplasia. Korean J Clin Pathol 2001;21:164-8.

5. Matsui Y, Yasui N, Kimura T, Tsumaki N, Kawabata H, Ochi T. Genotype phenotype correlation in achondroplasia and hypochondroplasia. J Bone Joint Surg Br 1998;80:1052-6.

6. Xue Y, Sun A, Mekikian PB, Martin J, Rimoin DL, Lachman RS, et al. FGFR3 mutation frequency in 324 cases from the International Skeletal Dysplasia Registry. Mol Genet Genomic Med 2014;2:497503.

7. Mustafa M, Moghrabi N, Bin-Abbas B. Hypochondroplasia, acanthosis nigricans, and insulin resistance in a child with FGFR3 mutation: is it just an association? Case Rep Endocrinol 2014;2014:840492.

8. Deng C, Wynshaw-Boris A, Zhou F, Kuo A, Leder P. Fibroblast growth factor receptor 3 is a negative regulator of bone growth. Cell 1996; 84:911-21.

9. Makrythanasis P, Temtamy S, Aglan MS, Otaify GA, Hamamy $H_{\text {, }}$ Antonarakis SE. A novel homozygous mutation in FGFR3 causes tall stature, severe lateral tibial deviation, scoliosis, hearing impairment, camptodactyly, and arachnodactyly. Hum Mutat 2014;35:959-63.

10. Takagi $M$, Kouwaki $M$, Kawase $K$, Shinohara $H$, Hasegawa $Y$, Yamada T, et al. A novel mutation Ser344Cys in FGFR3 causes achondroplasia with severe platyspondyly. Am J Med Genet A 2015;167A:2851-4.

11. Wynne-Davies R, Walsh WK, Gormley J. Achondroplasia and hypochondroplasia. Clinical variation and spinal stenosis. J Bone Joint Surg Br 1981;63B:508-15. 
12. Mortier G, Nuytinck L, Craen M, Renard JP, Leroy JG, de Paepe A. Clinical and radiographic features of a family with hypochondroplasia owing to a novel Asn540Ser mutation in the fibroblast growth factor receptor 3 gene. J Med Genet 2000;37:220-4.

13. Lamy M, Maroteaux P. Les chondrodystrophies génotypiques. Paris: L'Expansion Scientifique Francaise, 1961:26.

14. Beals RK. Hypochondroplasia. A report of five kindreds. J Bone Joint Surg Am 1969;51:728-36.

15. Specht EE, Daentl DL. Hypochondroplasia. Clin Orthop Relat Res
1975;(110):249-55.

16. Bellus GA, Hefferon TW, Ortiz de Luna RI, Hecht JT, Horton WA, Machado $M$, et al. Achondroplasia is defined by recurrent G380R mutations of FGFR3. Am J Hum Genet 1995;56:368-73.

17. Heuertz S, Le Merrer M, Zabel B, Wright M, Legeai-Mallet L, Cormier-

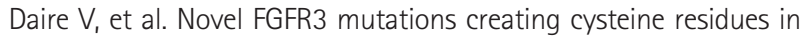
the extracellular domain of the receptor cause achondroplasia or severe forms of hypochondroplasia. Eur J Hum Genet 2006;14:12407. 